\title{
Cadherin Cell Adhesion System in Canine Mammary Cancer: A Review
}

\author{
Adelina Gama ${ }^{1}$ and Fernando Schmitt ${ }^{2,3}$ \\ ${ }^{1}$ Centro de Ciência Animal e Veterinária (CECAV), Universidade de Trás-os-Montes e Alto Douro (UTAD), \\ 5001-911 Vila Real, Portugal \\ ${ }^{2}$ Institute of Molecular Pathology and Immunology of the University of Porto (IPATIMUP), 4200-465 Porto, Portugal \\ ${ }^{3}$ Medical Faculty, University of Porto, 4200 Porto, Portugal \\ Correspondence should be addressed to Adelina Gama, agama@utad.pt
}

Received 16 April 2012; Accepted 15 July 2012

Academic Editor: Kazim Sahin

Copyright (C) 2012 A. Gama and F. Schmitt. This is an open access article distributed under the Creative Commons Attribution License, which permits unrestricted use, distribution, and reproduction in any medium, provided the original work is properly cited.

\begin{abstract}
Cadherin-catenin adhesion complexes play important roles by providing cell-cell adhesion and communication in different organ systems. Abnormal expression of cadherin adhesion molecules constitutes a common phenomenon in canine mammary cancer and has been frequently implicated in tumour progression. This paper summarizes the current knowledge on cadherin/catenin adhesion molecules (E-cadherin, $\beta$-catenin, and P-cadherin) in canine mammary cancer, focusing on the putative biological functions and clinical significance of these molecules in this disease. This paper highlights the need for further research studies in this setting in order to elucidate the role of these adhesion molecules during tumour progression and metastasis.
\end{abstract}

\section{Introduction}

In canine species, spontaneous mammary tumours constitute the second most frequent neoplasia, surpassed only by skin tumours. When considering female dogs, mammary tumours represent the most common neoplasia, with malignant tumours accounting for up to $50 \%$ of cases [1]. Therefore, this disease represents a serious problem in worldwide veterinary practice and is a matter of concern for both oncologists and pathologists, which is ultimately reflected on the escalating number of studies in this research area. Furthermore, canine mammary tumours have attracted considerable attention over the years as possible animal models for human mammary neoplasia, based on their morphological and biological similarities [2-4].

Mammary tumours of the female dog are commonly associated with the development of distant metastases, which ultimately leads to morbidity and mortality. In the initial steps of this complex biological process, neoplastic cells lose intercellular adhesion in order to invade local tissues, and it is now evident that tumour invasion and progression may result from changes in cell adhesion systems. Based on sequence homology and structure, cell adhesion molecules are divided into the following families: cadherins, selectins, integrins, the immunoglobulin superfamily, and lymphocyte homing receptors, such as CD44 [5]. In this paper, we will discuss the findings on cadherin-mediated cell adhesion systems in canine mammary cancer, focusing on the putative biological functions and clinical significance of these molecules in this disease.

\section{Overview of Cadherins}

Cadherins are calcium-dependent cell-cell adhesion molecules, believed to be essential in coordinating morphogenetic cell movements and in the maintenance of normal tissue architecture [6-8]. Over the last two decades, cadherin research has been focused on its possible implication in general carcinogenic pathways, including human breast and canine mammary cancer, as well as in its putative involvement in tumour cell invasion and progression.

Until now, more than 20 members of the cadherin family have been described, characterized by cell type-specific expression patterns [8], with classical cadherins being the 


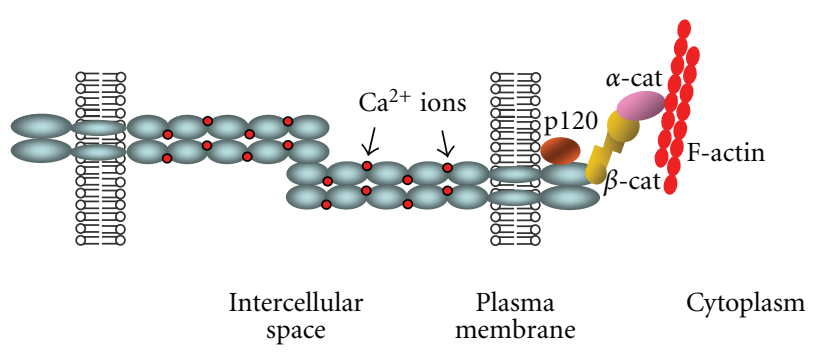

FIGURE 1: Schematic overview of the classical cadherin-catenin complex. Classical cadherins (blue), which mediate calciumdependent (red) intercellular adhesion, are composed by an extracellular domain, a transmembrane domain and a cytoplasmic domain. This one comprises a juxtamembrane domain, which binds to p120-catenin (orange), and a catenin-binding domain, which binds $\beta$-catenin (yellow). $\beta$-catenin binds to $\alpha$-catenin (violet), which establishes a direct link between the cadherincatenin complex and the actin cytoskeleton (red).

best characterised and most widely distributed members of the family [9].

Classical cadherins and their associated catenins form adhesion structures identified as adherens junctions [10]. Cadherins are single-pass transmembrane proteins comprising an extracellular domain, a transmembrane domain, and a cytoplasmic tail. The extracellular domain is composed of five cadherin repeats that are involved in promoting calcium-dependent homotypic cell-cell adhesion forming a zipper-like structure between neighbouring cells, while the intracellular domain interacts with cytoplasmic proteins termed catenins ( $\alpha$-, $\beta-, \gamma$-catenins), which link cadherins to the actin cytoskeleton (Figure 1) [10,11].

Epithelial (E-) cadherin (also called uvomorulin, L-Cam, cell-Cam 120/80, or Arc-1) was the first to be identified and constitutes the prototypic member of the classical cadherin family. E-cadherin is a $120 \mathrm{kDa}$ glycoprotein and is found in almost all epithelial tissues [12]. Other members include $\mathrm{P}$-cadherin (placental cadherin) and $\mathrm{N}$-cadherin (neuronal cadherin) $[9,13-15]$. P-cadherin was originally found to be highly expressed in mouse placenta throughout pregnancy and is restricted to the basal or lower layers of adult stratified epithelium $[9,12]$, whereas $\mathrm{N}$-cadherin is expressed by neuronal and muscle cells in human embryo and adult tissues [13].

The function and strength of cadherin-mediated adhesion depends on its dynamic association with catenins [16]. The cadherin cytoplasmic tail (catenin-binding domain, CBD) binds directly to $\beta$ - and $\gamma$-catenin, which in turn binds to $\alpha$-catenin to link the cadherin to the cytoskeleton, stabilizing the junctional structures $[11,17,18]$.

Besides being a cytoplasmic protein involved in linking cadherin family receptors to the actin cytoskeleton $[17,19$, 20], $\beta$-catenin is also a cotranscriptional activator of genes in the nucleus together with the lymphoid enhancer factor (LEF)/T-cell factor (TCF) [21-26], as a central component of the canonical Wnt signalling pathway [27]. Therefore, when free and stabilized in the cytoplasm, $\beta$-catenin promotes the activation of several genes, such as c-Myc and cyclin-D1, leading to changes in cell morphology, proliferation, and motility [28].

P120-catenin interacts directly with the juxtamembrane domain (JMD) of cytoplasmic tail and is regulated by tyrosine kinases, modulating cadherin intracellular trafficking, stability, adhesive capacity, and cell motility. Besides the interaction with p120 catenin, JMD supports lateral clustering and adhesive strengthening of cadherin complexes [29]. P120-catenin might modulate cell adhesion by influencing the organization of the actin cytoskeleton or by influencing the activity of RhoA, a small GTPase involved in actin cytoskeletal remodelling [30, 31].

Cell adhesion is a dynamic process regulated at various levels, including gene transcription, protein stability, and posttranslational modifications, in particular by phosphorylation of $\beta$-catenin and p120-catenin. Although intracellular signalling pathways (Wnt, TGF- $\beta$, MAPK) might affect cadherin-mediated adhesion, the establishment of adherens junctions also triggers signalling, which might involve Rho GTPases or growth factor receptors, such as EGFR [10]. The dynamic characteristics of the cadherin-catenin complex are important for embryogenesis and tissue repair, but can as well contribute to tumour development and progression [32], which has been scrutinized in detail, considering the amount of publications regarding this subject. In the following sections, the findings on cadherin-mediated cell adhesion systems in canine mammary cancer will be considered, as well as possible future directions in this spontaneous animal model.

\section{Cadherin and Catenins in Normal Canine Mammary Gland}

In normal canine mammary gland, E-cadherin and Pcadherin show a distinct pattern of expression. E-cadherin and $\beta$-catenin are expressed by epithelial cells [33-35], whereas expression of P-cadherin is restricted to myoepithelial cells (Figures 2(a), 2(c) and 2(d)), being P-cadherin a sensitive marker for this cell type [12, 36-38]. However, during lactation in humans and dogs, P-cadherin is not found at cell-cell borders, as expected for an adhesion molecule, but rather appears to be secreted by epithelial cells $[37,39]$.

\section{Cadherin and Catenins in Canine Mammary Cancer}

Despite the prolific studies in the human setting regarding cell adhesion implications in cancer, there are still few publications available in canine species. So, the specific role of cadherin-mediated cell adhesion in canine mammary cancer has not yet been fully revealed [33-35, 38, 40-45].

4.1. E-Cadherin. The vast majority of studies on cell adhesion involvement in tumourigenesis and invasion have focused on E-cadherin, given that this molecule is the major cadherin implicated in epithelial cell-cell adhesion, and the majority of tumours originate from epithelial cells [32]. 


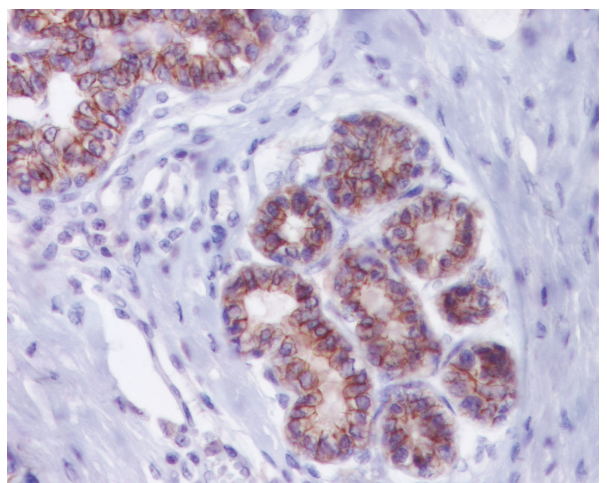

(a)

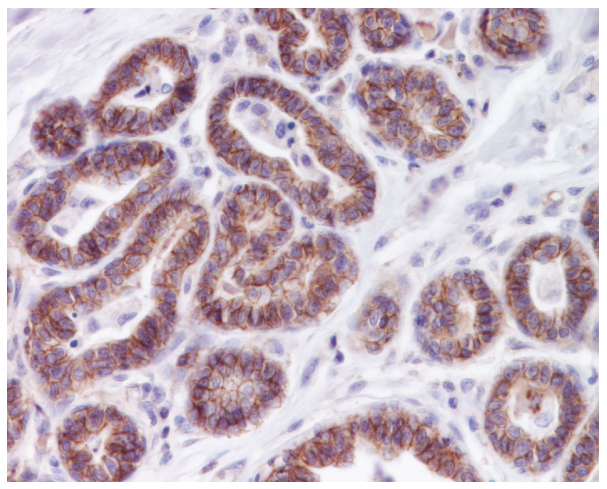

(c)

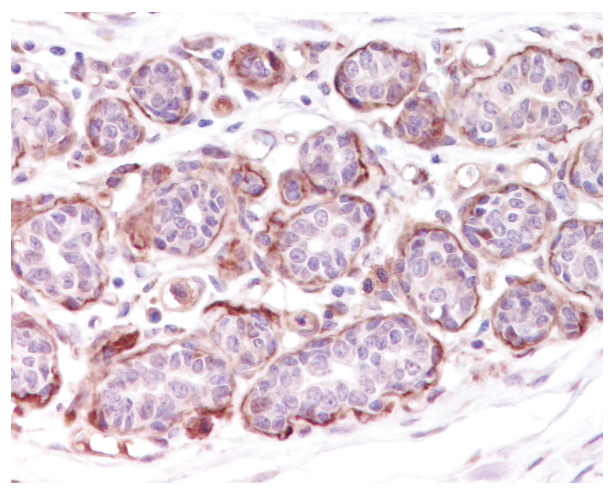

(e)

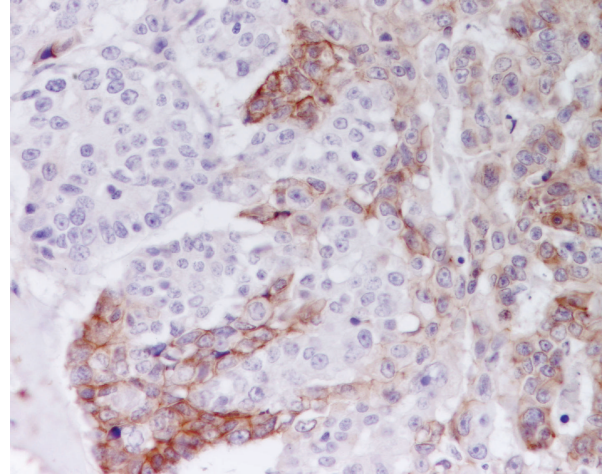

(b)

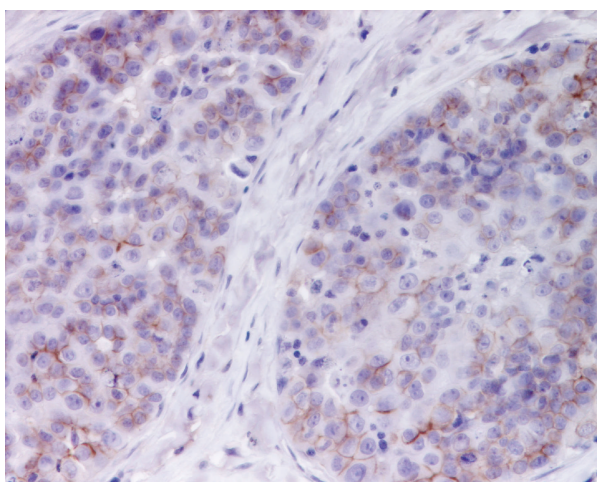

(d)

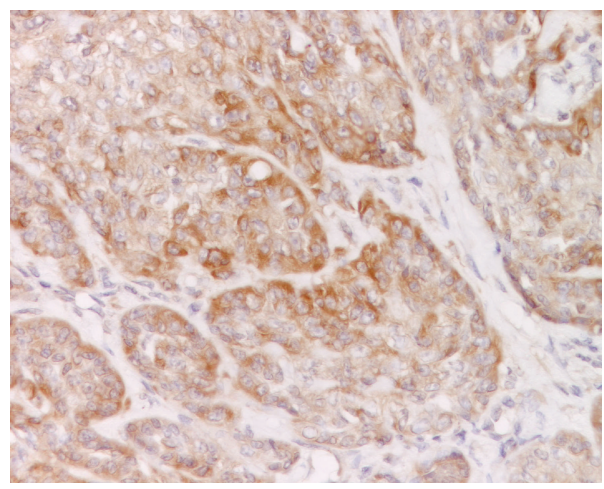

(f)

FIGURE 2: Immunohistochemical reactivity to adhesion molecules in canine mammary gland tissues. Normal mammary gland stained with antibodies to E-cadherin (a), $\beta$-catenin (c), and P-cadherin (e). Mammary carcinomas showing reduced expression for E-cadherin (b) and $\beta$-catenin (d), and aberrant expression for P-cadherin (f).

Thus, considering that an intact adhesion complex is required for the maintenance of normal intercellular adhesion, several studies dating back to the 1990s have proposed that E-cadherin might function as a tumour and invasion suppressor molecule such that a disturbed function of Ecadherin-catenin complex in theory enhances the tumour cell invasive potential [46].

There are several lines of evidence pointing out to Ecadherin tumour/invasion suppressor function, namely, in vitro and in vivo experiments demonstrating that E-cadherin downregulation promotes tumour progression and invasion $[18,47,48]$ and the presence of E-cadherin gene mutations in several human cancers, including human breast cancer [49]. In addition, the loss or reduction of the E-cadherin-catenin complex has been extensively associated with human breast cancer progression [50-56].

In 1997, Restucci and coworkers evaluated for the first time the immunohistochemical E-cadherin expression in canine mammary tumours, describing a reduced membranous expression in malignant neoplasia [33], especially in poorly undifferentiated cases, which was later on confirmed by other groups [35, 40], but not by others [42]. Reis et al. also found that the reduction of E-cadherin expression was significantly associated with malignancy, with all benign 
tumours analysed exhibiting a strong intercellular immunostaining [40].

According to our and other studies, reduced membranous expression of E-cadherin was significantly associated with tumour histological type. Solid-type carcinomas showed frequent loss of E-cadherin expression, in contrast to tubulopapillary carcinoma type $[35,40,42]$.

Human studies usually document the loss of E-cadherin in lobular carcinomas, which result from a mutational inactivation of E-cadherin gene, frequently associated with the loss of heterozygosity of the other allele [57]. In such tumours, E-cadherin acts as a typical tumour suppressor gene. Recently, Ressel et al. described the morphological and immunohistochemical features of three canine mammary tumours comparable with human infiltrating lobular carcinoma, which were also negative for E-cadherin, similarly to their human counterpart [58].

A number of investigators, including our group, reported that reduced E-cadherin expression was associated with invasion (Figure 2(b)) [34, 35, 41-43], and several classic prognostic features [42], namely, proliferation [59] and lymph node metastases, suggesting this molecule as a potential prognostic marker for canine mammary cancer $[35,43]$. In humans, some studies have not confirmed this relationship $[36,53,60]$ or indeed have associated Ecadherin expression with lymph node metastasis $[61,62]$. Ecadherin expression and function do not inevitably inhibit invasion, as it was demonstrated by Spieker and coworkers, by using an embryonic chicken heart assay [63]. Although expressing E-cadherin, canine mammary cell lines were all invasive in this in vitro study, which suggests that invasion depends upon other microenvironmental factors [63]. Recently, Nowak et al. found a negative correlation between E-cadherin and MMP9 expression in canine mammary carcinomas, suggesting that the loss of E-cadherin-mediated adhesion and the increase of MMP-9 could play an important role during tumour invasion [59].

The analysis of E-cadherin expression in lymph node metastases was rarely reported and several patterns of expression have been described, namely, downregulation, upregulation, or similar expression levels with regard to primary lesions $[40,64]$. According to Bukholm and Nesland, there is an E-cadherin reexpression on metastatic tissues, when compared to primary tumours [65]. This is probably related to the flexibility of adhesion complexes, which might be temporarily lost in primary tumours and recovered after reaching the metastatic site $[33,65]$. Probably, downregulation at primary site facilitates the detachment of cells and invasion, whereas at metastatic sites, the reexpression might allow the attachment of cancer cells [61]. This dynamic change in E-cadherin expression can be explained by promoter methylation or posttranslational regulation of cadherin-catenin complexes [32]. Recently, Pinho et al. pointed out to E-cadherin posttranslational modifications by $\mathrm{N}$-glycosylation during the acquisition of the malignant phenotype, which might explain this dynamic modulation [66].

However, it is unlikely that a single molecule can determine the acquisition of a less differentiated and more invasive neoplastic phenotype and other molecules must be considered in order to understand the complex mechanisms that lead to metastasis [33].

The expression of E-cadherin complex partner, $\beta$ catenin, has also been evaluated in canine mammary cancer. We and others found a significant positive association between these two proteins, which is consistent with the formation of adhesion complexes on the cell membrane $[35,41,43]$.

In addition, reduced membranous $\beta$-catenin expression was found to be significantly associated with high histological grade and invasion in several reports (Figure $2(\mathrm{~d})$ ) $[35,41]$, although not corroborated by Matos et al. [43]. No association has been described between reduced $\beta$-catenin and the presence of lymph node metastases [35, 43], which is similar to other human breast studies $[53,56,67]$.

The prognostic significance of E-cadherin and $\beta$-catenin expression in terms of survival of dogs with mammary carcinoma is debatable. Whereas Brunetti et al. found no association with survival, our group showed that loss/reduction of E-cadherin and $\beta$-catenin expression is significantly associated with shorter survival times $[35,41]$.

Although, in general, loss of E-cadherin expression correlates with undifferentiated human breast carcinomas, the available studies differ with regard to its association with survival and its value as a prognostic marker is still controversial [ $10,52,56,68-71]$. In fact, in neoplastic cells of one of the most aggressive forms of breast cancer, such as inflammatory breast cancer, the expression of E-cadherin is consistently elevated [72]. Charafe-Jauffret et al. also confirmed E-cadherin expression in this highly metastatic carcinoma, determining that E-cadherin expression is one of the key molecules of the "inflammatory signature" [73]. The author suggested that the loss of E-cadherin expression is a transient event that allows malignant cells to invade vascular channels and tissues and once in the circulation, cancer cells reexpress E-cadherin, facilitating intercellular adhesion and enabling the formation of cohesive tumour emboli. Our group observed the same pattern of expression in canine inflammatory mammary carcinomas, which were characterized by tumour emboli strongly positive for Ecadherin (Gama et al., unpublished data).

4.2. P-Cadherin. Besides E-cadherin, a number of canine mammary tumours also express P-cadherin cell adhesion molecule (Figure 2(f)) [38], which corroborates previous human findings. This molecule has been detected as altered in various human cancers, with P-cadherin found to be expressed by a subset of human breast carcinomas, but its exact role in the carcinogenic process still remains unclear [16].

In canine mammary tumours, a significant association was found between P-cadherin expression and tumour histological type [38]. However, more recently, when analysing a larger tumour series, P-cadherin expression was only significantly associated with an invasive tumour phenotype, with no association with other clinicopathological variables, proliferation, or survival [35].

Our results are discordant with the majority of available studies in human breast cancer, which found P-cadherin 
significantly associated with several aggressive characteristics, such as high histological grade and proliferation, as well as with a poor prognosis $[60,68,74-78]$, which has raised the interest on $\mathrm{P}$-cadherin as a potential prognostic marker for this disease.

With regard to histological types, P-cadherin is commonly identified in canine mammary carcinosarcoma and spindle cell carcinoma subtypes, as well as in human breast medullary and metaplastic carcinomas, which evokes for a basal/myoepithelial cell histogenetic origin or line of differentiation for these tumours $[38,79,80]$.

In human cancer studies, high-throughput microarray technologies allowed the distinction of breast cancer molecular subtypes (luminal A and B, HER-2 overexpressing, basallike, and claudin-low), with basal-like phenotype significantly associated with poor prognosis [81-85]. Ever since, several immunohistochemical surrogate panels have been suggested for the identification of this subgroup [86-88], and $\mathrm{P}$-cadherin is considered as one of the most sensitive biomarkers in distinguishing basal breast carcinomas $[16,78$, 89]. Similar to human findings, we have recently described P-cadherin expression significantly associated with a basallike phenotype in canine mammary carcinomas, which were characterized by poor prognostic features, such as high histological grade and proliferation, as well as with shorter disease-free and overall survival rates [90].

In our study, most luminal canine mammary carcinomas (ER positive) were P-cadherin negative [90]. P-cadherin expression was also found inversely correlated with hormonal receptor status in human breast carcinomas [75, $78,91]$ and it seems to be associated with an estrogenindependent tumour growth [75].

A number of hypotheses have been proposed to justify the anomalous expression of P-cadherin by breast cancer cells, namely, the oncofetal properties of P-cadherin protein [37], its histogenetic origin in cap cells or acquisition of a stem cell like phenotype $[68,74]$. However, although P-cadherin positive carcinomas seem to have a myoepithelial/basal-like transcriptomic programme, this reason probably does not account for every P-cadherin expressing tumour and it appears reasonable that certain molecular mechanisms would lead to the activation of Pcadherin expression during epithelial transformation [16].

In fact, a significant correlation was recently described between P-cadherin expression and hypomethylation of a specific region of the $\mathrm{CDH} 3$ promoter, suggesting an important regulatory role for cytosine methylation in the aberrant expression of P-cadherin in breast cancer [77]. On the other hand, the lack of ER signalling was found responsible for the increase in P-cadherin, categorizing $\mathrm{CDH} 3$ as an oestrogenrepressed gene and pointing to E2 as a key regulator of this cadherin [92]. In addition, it was shown that chromatinactivating modifications are also relevant in the modulation of P-cadherin gene, which suggests an additional epigenetic regulation [93].

Although the biofunctional role of P-cadherin in tumour progression is far from being fully elucidated, several in vitro studies using human breast $[92,94]$ and pancreatic [95] cancer cell lines have suggested a proinvasive role for this molecule, through its interaction with several signalling molecules, such as Rho GTPases and p120ctn $[94,95]$. This proinvasive activity depends on the JMD of the cytoplasmic tail, which binds to p120-catenin [92]. Recently, it was demonstrated that P-cadherin overexpression, in human breast cancer cells with wild-type E-cadherin, induces the secretion of matrix metalloproteases, specifically MMP1 and MMP-2 and promotes cell invasion, motility, and migration, due to a mechanism involving alterations in the actin cytoskeleton and signalling through small GTPasebinding proteins [94]. Taking into account its role in cancer cell invasion, a selective human monoclonal antibody was recently produced against $\mathrm{P}$-cadherin, which is currently under Phase I clinical trials [96].

Besides breast cancer, P-cadherin has been studied in several human cancers, and it seems to behave differently depending on the cancer model [16]. In canine mammary cancer, novel investigations are welcome in order to unravel $\mathrm{P}$-cadherin potential role in tumour progression. Whether it represents a useful prognostic marker or plays a causal role is still open to question.

\section{Conclusion and Future Perspectives}

Taken together, the overall findings in canine mammary cancer suggest a possible role for E-cadherin-mediated adhesion in preventing invasion and metastasis in this animal model, corroborating human breast cancer studies. Yet, results are not consensual and larger controlled studies are required in order to definitively determine cell adhesion implication in the multifaceted metastatic process, as well as the usefulness of cadherins and catenins as valuable prognostic markers and potential therapeutic targets for canine mammary carcinomas.

\section{Acknowledgment}

The work was supported by the strategic Research Project PEst-OE/AGR/UI0772/2011 financed by the Foundation for Science and Technology (FCT).

\section{References}

[1] W. Misdorp, "Tumours of the mammary gland," in Tumors in Domestic Animals, D. J. Meuten, Ed., pp. 575-606, Iowa State Press, Blackwell, Ames, Iowa, USA, 4th edition, 2002.

[2] S. R. Gilbertson, I. D. Kurzman, and R. E. Zachrau, "Canine mammary epithelial neoplasms: biologic implications of morphologic characteristics assessed in 232 dogs," Veterinary Pathology, vol. 20, no. 2, pp. 127-142, 1983.

[3] C. Khanna, K. Lindblad-Toh, D. Vail et al., "The dog as a cancer model," Nature Biotechnology, vol. 24, no. 9, pp. 10651066, 2006.

[4] P. N. Olson, "Using the canine genome to cure cancer and other diseases," Theriogenology, vol. 68, no. 3, pp. 378-381, 2007.

[5] N. Makrilia, A. Kollias, L. Manolopoulos, and K. Syrigos, "Cell adhesion molecules: role and clinical significance in cancer," Cancer Investigation, vol. 27, no. 10, pp. 1023-1037, 2009. 
[6] M. Takeichi, "Cadherin cell adhesion receptors as a morphogenetic regulator," Science, vol. 251, no. 5000, pp. 1451-1455, 1991.

[7] B. M. Gumbiner, "Cell adhesion: the molecular basis of tissue architecture and morphogenesis," Cell, vol. 84, no. 3, pp. 345357, 1996.

[8] D. M. Li and Y. M. Feng, "Signaling mechanism of cell adhesion molecules in breast cancer metastasis: potential therapeutic targets," Breast Cancer Research and Treatment, vol. 128, no. 1, pp. 7-21, 2011.

[9] A. Nose and M. Takeichi, "A novel cadherin cell adhesion molecule: its expression patterns associated with implantation and organogenesis of mouse embryos," Journal of Cell Biology, vol. 103, no. 6, pp. 2649-2658, 1986.

[10] K. A. Knudsen and M. J. Wheelock, "Cadherins and the mammary gland," Journal of Cellular Biochemistry, vol. 95, no. 3, pp. 488-496, 2005.

[11] K. A. Knudsen, C. Frankowski, K. R. Johnson, and M. J. Wheelock, "A role for cadherins in cellular signaling and differentiation," Journal of Cellular Biochemistry. Supplement, vol. 30-31, pp. 168-176, 1998.

[12] Y. Shimoyama, T. Yoshida, M. Terada, Y. Shimosato, O. Abe, and S. Hirohashi, "Molecular cloning of a human $\mathrm{Ca}^{2+}$ dependent cell-cell adhesion molecule homologous to mouse placental cadherin: its low expression in human placental tissues," Journal of Cell Biology, vol. 109, no. 4 I, pp. 1787-1794, 1989.

[13] K. Hatta and M. Takeichi, "Expression of N-cadherin adhesion molecules associated with early morphogenetic events in chick development," Nature, vol. 320, no. 6061, pp. 447-449, 1986.

[14] A. Nose, A. Nagafuchi, and M. Takeichi, "Isolation of placental cadherin cDNA: identification of a novel gene family of cellcell adhesion molecules," The EMBO Journal, vol. 6, no. 12, pp. 3655-3661, 1987.

[15] S. Miyatani, K. Shimamura, M. Hatta et al., "Neural cadherin: role in selective cell-cell adhesion," Science, vol. 245, no. 4918, pp. 631-635, 1989.

[16] J. Paredes, A. L. Correia, A. S. Ribeiro, A. Albergaria, F. Milanezi, and F. C. Schmitt, "P-cadherin expression in breast cancer: a review," Breast Cancer Research, vol. 9, no. 5, p. 214, 2007.

[17] M. Ozawa, H. Barbault, and R. Kemler, "The cytoplasmic domain of the cell adhesion molecule uvomorulin assoicates with three independent proteins structurally related in different species," The EMBO Journal, vol. 8, no. 6, pp. 1711-1717, 1989.

[18] K. Vleminckx, L. Vakaet Jr., M. Mareel, W. Fiers, and F. Van Roy, "Genetic manipulation of E-cadherin expression by epithelial tumor cells reveals an invasion suppressor role," Cell, vol. 66, no. 1, pp. 107-119, 1991.

[19] P. D. McCrea, C. W. Turck, and B. Gumbiner, "A homolog of the armadillo protein in Drosophila (plakoglobin) associated with E-cadherin," Science, vol. 254, no. 5036, pp. 1359-1361, 1991.

[20] M. Peifer, P. D. McCrea, K. J. Green, E. Wieschaus, and B. M. Gumbiner, "The vertebrate adhesive junction proteins $\beta$ catenin and plakoglobin and the Drosophila segment polarity gene armadillo form a multigene family with similar properties," Journal of Cell Biology, vol. 118, no. 3, pp. 681-691, 1992.

[21] J. Behrens, J. P. Von Kries, M. Kühl et al., "Functional interaction of $\beta$-catenin with the transcription factor LEF-1," Nature, vol. 382, no. 6592, pp. 638-642, 1996.

[22] O. Huber, R. Korn, J. McLaughlin, M. Ohsugi, B. G. Herrmann, and R. Kemler, "Nuclear localization of $\beta$-catenin by interaction with transcription factor LEF-1," Mechanisms of Development, vol. 59, no. 1, pp. 3-10, 1996.

[23] M. Molenaar, M. van de Wetering, M. Oosterwegel et al., "XTcf-3 transcription factor mediates $\beta$-catenin-induced axis formation in xenopus embryos," Cell, vol. 86, no. 3, pp. 391399, 1996.

[24] M. van de Wetering, R. Cavallo, D. Dooijes et al., "Armadillo coactivates transcription driven by the product of the Drosophila segment polarity gene dTCF," Cell, vol. 88, no. 6, pp. 789-799, 1997.

[25] G. Berx and F. Van Roy, "The E-cadherin/catenin complex: an important gatekeeper in breast cancer tumorigenesis and malignant progression," Breast Cancer Research, vol. 3, no. 5, pp. 289-293, 2001.

[26] A. M. C. Brown, "Wnt signaling in breast cancer: have we come full circle?" Breast Cancer Research, vol. 3, no. 6, pp. 351355, 2001.

[27] N. Gavert and A. Ben-Ze'ev, “ $\beta$-catenin signaling in biological control and cancer," Journal of Cellular Biochemistry, vol. 102, no. 4, pp. 820-828, 2007.

[28] T. M. Rowlands, I. V. Pechenkina, S. J. Hatsell, R. G. Pestell, and P. Cowin, "Dissecting the roles of $\beta$-catenin and cyclin D1 during mammary development and neoplasia," Proceedings of the National Academy of Sciences of the United States of America, vol. 100, no. 20, pp. 11400-11405, 2003.

[29] A. S. Yap, C. M. Niessen, and B. M. Gumbiner, "The juxtamembrane region of the cadherin cytoplasmic tail supports lateral clustering, adhesive strengthening, and interaction with p120 ctn , Journal of Cell Biology, vol. 141, no. 3, pp. 779-789, 1998.

[30] T. Ohkubo and M. Ozawa, "p120 ctn binds to the membraneproximal region of the E-cadherin cytoplasmic domain and is involved in modulation of adhesion activity," The Journal of Biological Chemistry, vol. 274, no. 30, pp. 21409-21415, 1999.

[31] P. Z. Anastasiadis, S. Y. Moon, M. A. Thoreson et al., "Inhibition of RhoA by p120 catenin," Nature Cell Biology, vol. 2, no. 9, pp. 637-644, 2000.

[32] M. J. Wheelock, A. P. Soler, and K. A. Knudsen, "Cadherin junctions in mammary tumors," Journal of Mammary Gland Biology and Neoplasia, vol. 6, no. 3, pp. 275-285, 2001.

[33] B. Restucci, S. Papparella, G. De Vico, and P. Maiolino, "E cadherin expression in normal and neoplastic canine mammary gland," Journal of Comparative Pathology, vol. 116, no. 2, pp. 191-202, 1997.

[34] G. Sarli, R. Preziosi, L. De Tolla, B. Brunetti, and C. Benazzi, "E-cadherin immunoreactivity in canine mammary tumors," Journal of Veterinary Diagnostic Investigation, vol. 16, no. 6, pp. 542-547, 2004.

[35] A. Gama, J. Paredes, F. Gärtner, A. Alves, and F. Schmitt, "Expression of E-cadherin, P-cadherin and $\beta$-catenin in canine malignant mammary tumours in relation to clinicopathological parameters, proliferation and survival," Veterinary Journal, vol. 177, no. 1, pp. 45-53, 2008.

[36] J. Palacios, N. Benito, A. Pizarro et al., "Anomalous expression of P-cadherin in breast carcinoma: correlation with E-cadherin expression and pathological features," American Journal of Pathology, vol. 146, no. 3, pp. 605-612, 1995.

[37] A. Gama, J. Paredes, M. F. Milanezi, J. S. Reis-Filho, F. Gartner, and F. C. Schmitt, "P-cadherin expression in canine lactating mammary gland," Journal of Cellular Biochemistry, vol. 86, no. 3, pp. 420-421, 2002.

[38] A. Gama, J. Paredes, A. Albergaria, F. Gartner, and F. Schmitt, "P-cadherin expression in canine mammary tissues," Journal of Comparative Pathology, vol. 130, no. 1, pp. 13-20, 2004. 
[39] A. P. Soler, J. Russo, I. H. Russo, and K. A. Knudsen E, "Soluble fragment of P-cadherin adhesion protein found in human milk," Journal of Cellular Biochemistry, vol. 85, no. 1, pp. 180 184, 2002.

[40] A. L. Reis, J. Carvalheira, F. C. Schmitt, and F. Gärtner, "Immunohistochemical study of the expression of E-cadherin in canine mammary tumours," Veterinary Record, vol. 152, no. 20, pp. 621-624, 2003.

[41] B. Brunetti, G. Sarli, R. Preziosi, I. Monari, and C. Benazzi, "E-cadherin and $\beta$-catenin reduction influence invasion but not proliferation and survival in canine malignant mammary tumors," Veterinary Pathology, vol. 42, no. 6, pp. 781-787, 2005.

[42] A. J. F. Matos, C. Lopes, J. Carvalheira, M. Santos, G. R. Rutteman, and F. Gärtner, "E-cadherin expression in canine malignant mammary tumours: relationship to other clinicopathological variables," Journal of Comparative Pathology, vol. 134, no. 2-3, pp. 182-189, 2006.

[43] A. J. F. de Matos, C. C. C. Lopes, A. M. R. Faustino, J. G. V. Carvalheira, G. R. Rutteman, and M. D. F. R. M. Gärtner, "E-cadherin, $\beta$-catenin, invasion and lymph node metastases in canine malignant mammary tumours," Acta Pathologica, Microbiologica et Immunologica, vol. 115, no. 4, pp. 327-334, 2007.

[44] M. Nowak, J. A. Madej, and P. Dziegiel, "Expression of Ecadherin, $\beta$-catenin and Ki-67 antigen and their reciprocal relationships in mammary adenocarcinomas in bitches," Folia Histochemica et Cytobiologica, vol. 45, no. 3, pp. 233-238, 2007.

[45] A. Rodo and E. Malicka, "E-cadherin immimohistochemical expression in mammary gland neoplasms in bitches," Polish Journal of Veterinary Sciences, vol. 11, no. 1, pp. 47-54, 2008.

[46] B. P. L. Wijnhoven, W. N. M. Dinjens, and M. Pignatelli, "E-cadherin-catenin cell-cell adhesion complex and human cancer," British Journal of Surgery, vol. 87, no. 8, pp. 992-1005, 2000.

[47] U. H. Frixen, J. Behrens, M. Sachs et al., "E-cadherin-mediated cell-cell adhesion prevents invasiveness of human carcinoma cells," Journal of Cell Biology, vol. 113, no. 1, pp. 173-185, 1991.

[48] A. K. Peri, P. Wilgenbus, U. Dahl, H. Semb, and G. Christofori, "A causal role for E-cadherin in the transition from adenoma to carcinoma," Nature, vol. 392, no. 6672, pp. 190-193, 1998.

[49] C. B. J. Vos, A. M. Cleton-Jansen, G. Berx et al., "E-cadherin inactivation in lobular carcinoma in situ of the breast: an early event in tumerigenesis," British Journal of Cancer, vol. 76, no. 9, pp. 1131-1133, 1997.

[50] C. Gamallo, J. Palacios, A. Suarez et al., "Correlation of Ecadherin expression with differentiation grade and histological type in breast carcinoma," American Journal of Pathology, vol. 142, no. 4, pp. 987-993, 1993.

[51] H. Oka, H. Shiozaki, K. Kobayashi et al., "Expression of Ecadherin cell adhesion molecules in human breast cancer tissues and its relationship to metastasis," Cancer Research, vol. 53, no. 7, pp. 1696-1701, 1993.

[52] S. M. Siitonen, J. T. Kononen, H. J. Helin, I. S. Rantala, K. A. Holli, and J. J. Isola, "Reduced E-cadherin expression is associated with invasiveness and unfavorable prognosis in breast cancer," American Journal of Clinical Pathology, vol. 105, no. 4, pp. 394-402, 1996.

[53] I. K. Bukholm, J. M. Nesland, R. Karesen, U. Jacobsen, and A. L. Borresen-Dale, "E-cadherin and alpha-, beta-, and gammacatenin protein expression in relation to metastasis in human breast carcinoma," Journal of Pathology, vol. 185, pp. 262-266, 1998.
[54] R. Heimann, F. Lan, R. McBride, and S. Hellman, "Separating favorable from unfavorable prognostic markers in breast cancer: the role of E-cadherin," Cancer Research, vol. 60, no. 2, pp. 298-304, 2000.

[55] M. Madhavan, P. Srinivas, E. Abraham et al., "Cadherins as predictive markers of nodal metastasis in breast cancer," Modern Pathology, vol. 14, no. 5, pp. 423-427, 2001.

[56] R. Yoshida, N. Kimura, Y. Harada, and N. Ohuchi, "The loss of E-cadherin, alpha- and beta-catenin expression is associated with metastasis and poor prognosis in invasive breast cancer," International Journal of Oncology, vol. 18, no. 3, pp. 513-520, 2001.

[57] G. Berx, A. M. Cleton-Jansen, F. Nollet et al., "E-cadherin is a tumour/invasion suppressor gene mutated in human lobular breast cancers," The EMBO Journal, vol. 14, no. 24, pp. 61076115, 1995.

[58] L. Ressel, F. Millanta, and A. Poli, "Canine invasive lobular carcinoma of the mammary gland: morphological and immunohistochemical characterizations of three cases," Journal of Comparative Pathology, vol. 144, no. 4, pp. 303-307, 2011.

[59] M. Nowak, J. A. Madej, M. Podhorska-Okolow, and P. Dziegiel, "Expression of extracellular matrix metalloproteinase (MMP-9), E-cadherin and proliferation-associated antigen $\mathrm{Ki}-67$ and their reciprocal correlation in canine mammary adenocarcinomas," In Vivo, vol. 22, no. 4, pp. 463470, 2008.

[60] A. Kovács, J. Dhillon, and R. A. Walker, "Expression of Pcadherin, but not E-cadherin or N-cadherin, relates to pathological and functional differentiation of breast carcinomas," Journal of Clinical Pathology, vol. 56, no. 6, pp. 318-322, 2003.

[61] C. E. Gillett, D. W. Miles, K. Ryder et al., "Retention of the expression of E-cadherin and catenins is associated with shorter survival in grade III ductal carcinoma of the breast," Journal of Pathology, vol. 193, no. 4, pp. 433-441, 2001.

[62] E. M. Howard, S. K. Lau, R. H. Lyles, G. G. Birdsong, J. N. Umbreit, and R. Kochhar, "Expression of E-cadherin in highrisk breast cancer," Journal of Cancer Research and Clinical Oncology, vol. 131, no. 1, pp. 14-18, 2005.

[63] N. Spieker, M. Mareel, E. A. Bruyneel, and H. Nederbragt, "Ecadherin expression and in vitro invasion of canine mammary tumor cells," European Journal of Cell Biology, vol. 68, no. 4, pp. 427-436, 1995.

[64] B. Brunetti, G. Sarli, R. Preziosi, S. Leprotti, and C. Benazzi, "E-cadherin expression in canine mammary carcinomas with regional lymph node metastases," Journal of Veterinary Medicine A, vol. 50, no. 10, pp. 496-500, 2003.

[65] I. K. Bukholm and J. M. Nesland, "Re-expression of Ecadherin, $\alpha$-catenin and $\beta$-catenin, but not of $\gamma$-catenin, in metastatic tissue from breast cancer patients," ,Journal of Pathology, vol. 190, pp. 15-19, 2000.

[66] S. S. Pinho, H. Osório, M. Nita-Lazar et al., "Role of E-cadherin $\mathrm{N}$-glycosylation profile in a mammary tumor model," Biochemical and Biophysical Research Communications, vol. 379, no. 4, pp. 1091-1096, 2009.

[67] M. A. Gonzalez, S. E. Pinder, P. M. Wencyk et al., "An immunohistochemical examination of the expression of Ecadherin, alpha- and beta/gamma-catenins, and alpha2- and beta1-integrins in invasive breast cancer," Journal of Pathology, vol. 187, pp. 523-529, 1999.

[68] A. Soler, K. A. Knudsen, H. Salazar, A. C. Han, and A. A. Keshgegian, "P-cadherin expression in breast carcinoma indicates poor survival," Cancer, vol. 86, pp. 1263-1272, 1999. 
[69] M. Dolled-Filhart, A. McCabe, J. Giltnane, M. Cregger, R. L. Camp, and D. L. Rimm, "Quantitative in situ analysis of $\beta$-catenin expression in breast cancer shows decreased expression is associated with poor outcome," Cancer Research, vol. 66, no. 10, pp. 5487-5494, 2006.

[70] B. E. Gould Rothberg and M. B. Bracken, "E-cadherin immunohistochemical expression as a prognostic factor in infiltrating ductal carcinoma of the breast: a systematic review and meta-analysis," Breast Cancer Research and Treatment, vol. 100, no. 2, pp. 139-148, 2006.

[71] D. Park, R. Kåresen, U. Axcrona, T. Noren, and T. Sauer, "Expression pattern of adhesion molecules (E-cadherin, $\alpha$-, $\beta-, \gamma$-catenin and claudin-7), their influence on survival in primary breast carcinoma, and their corresponding axillary lymph node metastasis," Acta Pathologica, Microbiologica et Immunologica, vol. 115, no. 1, pp. 52-65, 2007.

[72] C. G. Kleer, K. L. van Golen, T. Braun, and S. D. Merajver, "Persistent E-cadherin expression in inflammatory breast cancer," Modern Pathology, vol. 14, no. 5, pp. 458-464, 2001.

[73] E. Charafe-Jauffret, C. Tarpin, V. J. Bardou et al., "Immunophenotypic analysis of inflammatory breast cancers: identification of an 'inflammatory signature," Journal of Pathology, vol. 202, no. 3, pp. 265-273, 2004.

[74] C. Gamallo, G. Moreno-Bueno, D. Sarrió, F. Calero, D. Hardisson, and J. Palacios, "The prognostic significance of P-cadherin in infiltrating ductal breast carcinoma," Modern Pathology, vol. 14, no. 7, pp. 650-654, 2001.

[75] J. Paredes, F. Milanezi, J. S. Reis-Filho, D. Leitão, D. Athanazio, and F. Schmitt, "Aberrant P-cadherin expression: is it associated with estrogen-independent growth in breast cancer?" Pathology Research and Practice, vol. 198, no. 12, pp. 795-801, 2002.

[76] J. B. Arnes, J. S. Brunet, I. Stefansson et al., "Placental cadherin and the basal epithelial phenotype of BRCA1-related breast cancer," Clinical Cancer Research, vol. 11, no. 11, pp. 40034011, 2005.

[77] J. Paredes, A. Albergaria, J. T. Oliveira, C. Jeronimo, F. Milanezi, and F. C. Schmitt, "P-cadherin overexpression is an indicator of clinical outcome in invasive breast carcinomas and is associated with $\mathrm{CDH} 3$ promoter hypomethylation," Clinical Cancer Research, vol. 11, no. 16, pp. 5869-5877, 2005.

[78] G. Turashvili, S. E. McKinney, O. Goktepe et al., "P-cadherin expression as a prognostic biomarker in a 3992 case tissue microarray series of breast cancer," Modern Pathology, vol. 24, no. 1, pp. 64-81, 2011.

[79] A. C. Han, A. P. Soler, K. A. Knudsen, and H. Salazar, "Distinct cadherin profiles in special variant carcinomas and other tumors of the breast," Human Pathology, vol. 30, no. 9, pp. 1035-1039, 1999.

[80] J. S. Reis-Filho, F. Milanezi, J. Paredes et al., "Novel and classic myoepithelial/stem cell markers in metaplastic carcinomas of the breast," Applied Immunohistochemistry and Molecular Morphology, vol. 11, no. 1, pp. 1-8, 2003.

[81] C. M. Perou, T. Sørile, M. B. Eisen et al., "Molecular portraits of human breast tumours," Nature, vol. 406, no. 6797, pp. 747$752,2000$.

[82] T. Sørlie, C. M. Perou, R. Tibshirani et al., "Gene expression patterns of breast carcinomas distinguish tumor subclasses with clinical implications," Proceedings of the National Academy of Sciences of the United States of America, vol. 98, no. 19, pp. 10869-10874, 2001.

[83] T. Sørlie, R. Tibshirani, J. Parker et al., "Repeated observation of breast tumor subtypes in independent gene expression data sets," Proceedings of the National Academy of Sciences of the United States of America, vol. 100, no. 14, pp. 8418-8423, 2003.

[84] C. Sotiriou, S. Y. Neo, L. M. McShane et al., "Breast cancer classification and prognosis based on gene expression profiles from a population-based study," Proceedings of the National Academy of Sciences of the United States of America, vol. 100, no. 18, pp. 10393-10398, 2003.

[85] A. Prat, J. S. Parker, O. Karginova et al., "Phenotypic and molecular characterization of the claudin-low intrinsic subtype of breast cancer," Breast Cancer Research, vol. 12, no. 5, article R68, 2010.

[86] T. O. Nielsen, F. D. Hsu, K. Jensen et al., "Immunohistochemical and clinical characterization of the basal-like subtype of invasive breast carcinoma," Clinical Cancer Research, vol. 10, no. 16, pp. 5367-5374, 2004.

[87] I. Matos, R. Dufloth, M. Alvarenga, L. C. Zeferino, and F. Schmitt, "p63, cytokeratin 5, and P-cadherin: three molecular markers to distinguish basal phenotype in breast carcinomas," Virchows Archiv, vol. 447, no. 4, pp. 688-694, 2005.

[88] E. A. Rakha, M. E. El-Sayed, J. Reis-Filho, and I. O. Ellis, "Patho-biological aspects of basal-like breast cancer," Breast Cancer Research and Treatment, vol. 113, no. 3, pp. 411-422, 2009.

[89] B. Sousa, J. Paredes, F. Milanezi et al., "P-cadherin, Vimentin and CK14 for identification of basal-like phenotype in breast carcinomas: an immunohistochemical study," Histology and Histopathology, vol. 25, no. 8, pp. 963-974, 2010.

[90] A. Gama, A. Alves, and F. Schmitt, "Identification of molecular phenotypes in canine mammary carcinomas with clinical implications: application of the human classification," Virchows Archiv, vol. 453, no. 2, pp. 123-132, 2008.

[91] J. C. Paredes, M. F. G. Milanezi, J. S. Reis-Filho, D. R. A. Leitão, D. A. Athanazio, and F. C. De Landér Schmitt, "Correlation between P-cadherin and estrogen receptor expression in breast cancer," Jornal Brasileiro de Patologia e Medicina Laboratorial, vol. 38, no. 4, pp. 307-313, 2002.

[92] J. Paredes, C. Stove, V. Stove et al., "P-cadherin is up-regulated by the antiestrogen ICI 182,780 and promotes invasion of human breast cancer cells," Cancer Research, vol. 64, no. 22, pp. 8309-8317, 2004.

[93] A. Albergaria, A. S. Ribeiro, S. Pinho et al., "ICI 182,780 induces P-cadherin overexpression in breast cancer cells through chromatin remodelling at the promoter level: a role for $\mathrm{C} / \mathrm{EBP} \beta$ in $\mathrm{CDH} 3$ gene activation," Human Molecular Genetics, vol. 19, no. 13, pp. 2554-2566, 2010.

[94] A. S. Ribeiro, A. Albergaria, B. Sousa et al., "Extracellular cleavage and shedding of P-cadherin: a mechanism underlying the invasive behaviour of breast cancer cells," Oncogene, vol. 29, no. 3, pp. 392-402, 2010.

[95] K. Taniuchi, H. Nakagawa, M. Hosokawa et al., "Overexpressed P-cadherin/CDH3 promotes motility of pancreatic cancer cells by interacting with p120ctn and activating Rhofamily GTPases," Cancer Research, vol. 65, no. 8, pp. 30923099, 2005.

[96] C. C. Zhang, Z. Yan, Q. Zhang et al., "PF-03732010: a fully human monoclonal antibody against P-cadherin with antitumor and antimetastatic activity," Clinical Cancer Research, vol. 16, no. 21, pp. 5177-5188, 2010. 

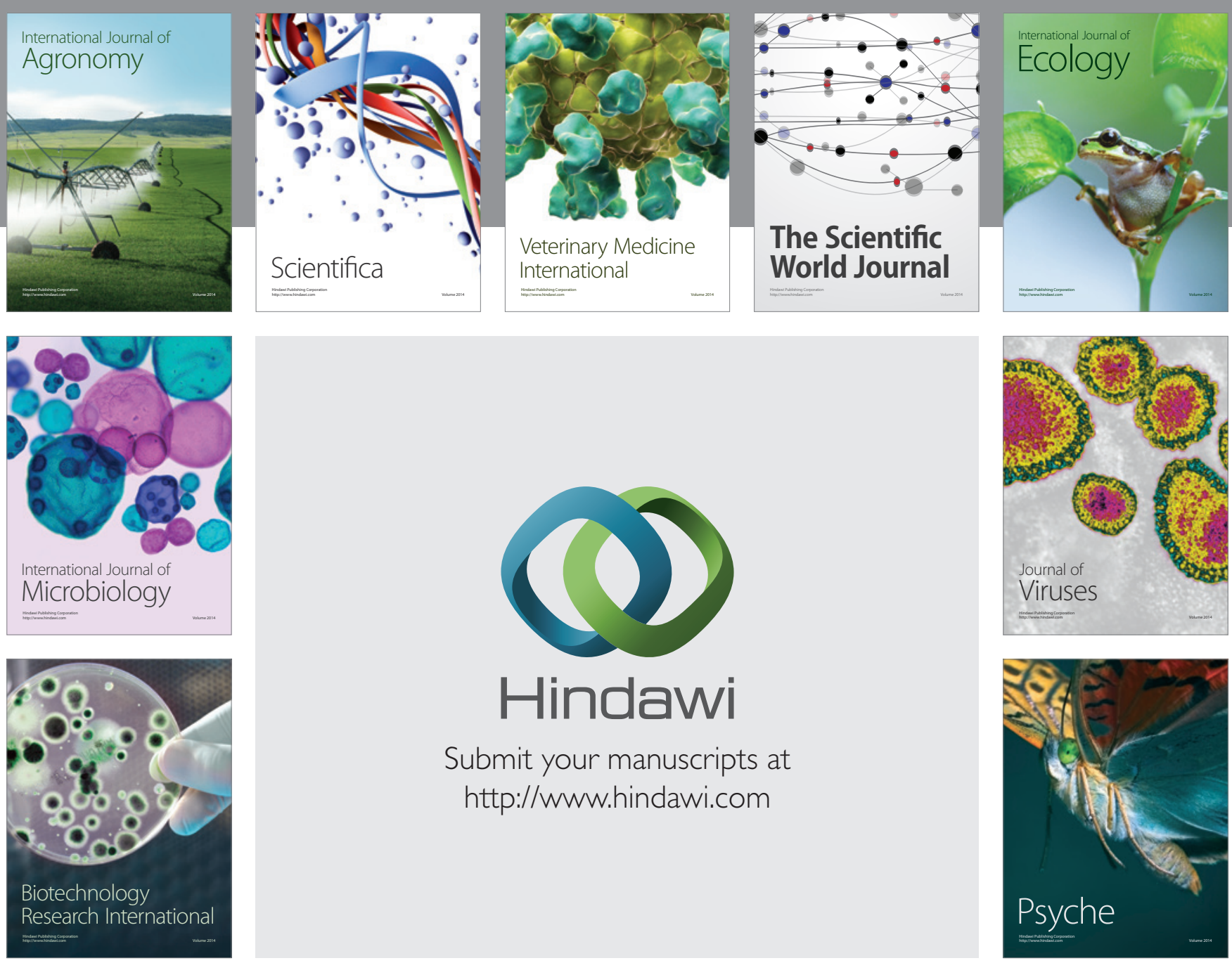

Submit your manuscripts at

http://www.hindawi.com
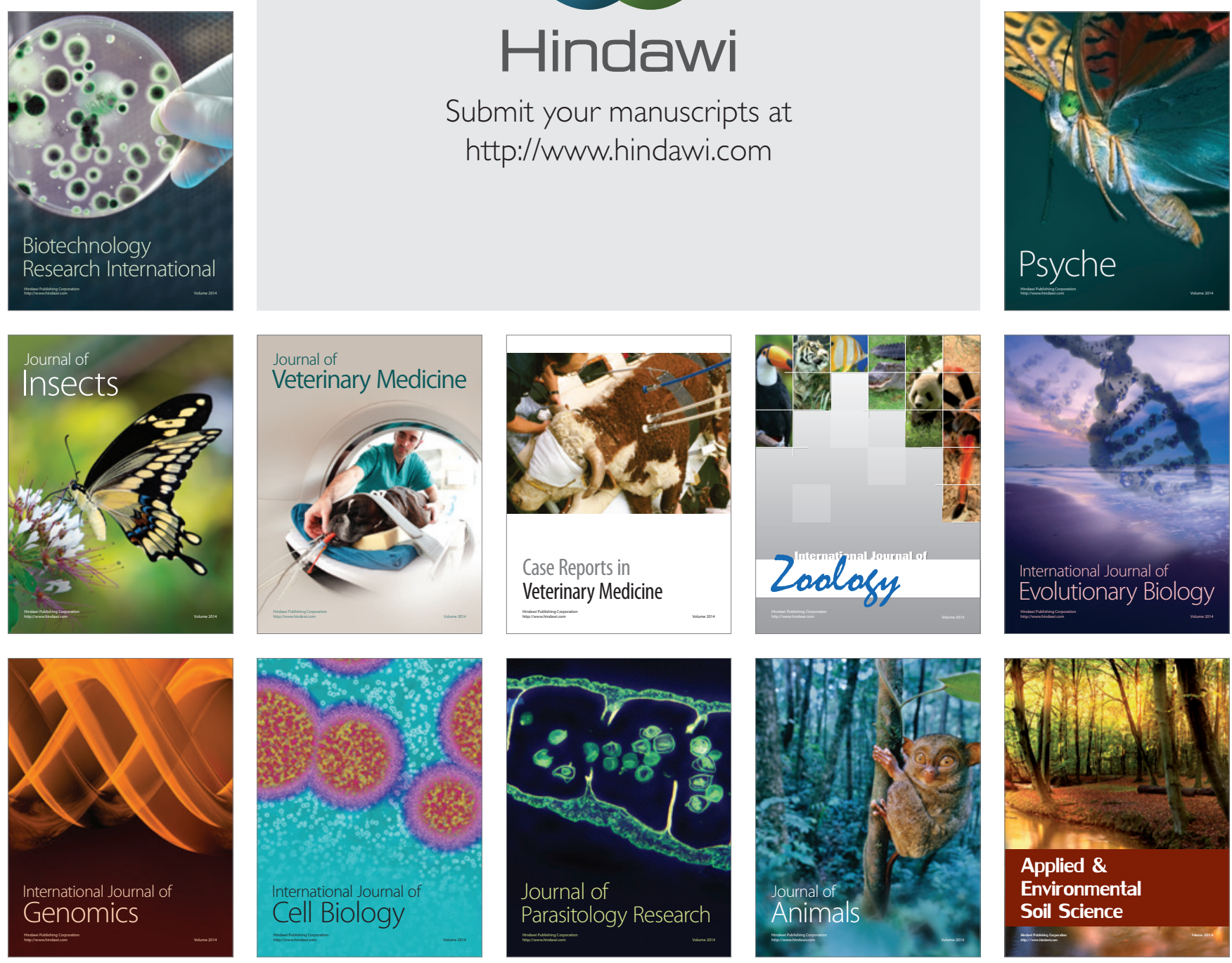